\title{
EFEITO DA COMPETIÇÃO DE PLANTAS DANINHAS NA CULTURA DO FEIJOEIRO
}

\author{
EFFECT OF WEED COMPETITION IN BEAN
}

\author{
Paula Masami Sano MANABE ${ }^{1}$; Christiano da Conceição de MATOS ${ }^{2}$; \\ Evander Alves FERREIRA ${ }^{3}$; Alexandre Ferreira da SILVA ${ }^{4}$; \\ Antônio Alberto da SILVA ${ }^{5}$; Tocio SEDIYAMA ${ }^{5}$; Akihiko MANABE; \\ Paulo Roberto Ribeiro ROCHA ${ }^{7}$; Cícero Teixeira da SILVA ${ }^{8}$
}

1. Engenheira Agrônoma, Universidade Federal de Viçosa - UFV, Viçosa, MG, Brasil. paulasano@gmail.com; 2. Doutorando em Fitotecnia, Universidade Federal de Viçosa - UFV, Viçosa, MG, Brasil; 3. Pós doutorando em Produção Vegetal, Universidade Federal dos Vales do Jequitinhonha e Mucuri, Diamantina, MG, Brasil; 4. Pesquisador, Doutor, Embrapa Milho e Sorgo, Sinop, MT, Brasil; 5. Professor, Doutor, Programa de Pós Graduação em Fitotecnia - UFV, Viçosa, MG, Brasil; 6. Professor, Mestre, Centro Universitário Augusto Motta, Rio de Janeiro, RJ, Brasil; 7. Professor, Doutor, Departamento de Agronomia da Universidade Federal de Roraima, RR. Brasil; 8. Mestrando em Produção Vegetal, Universidade Federal dos Vales do Jequitinhonha e Mucuri, Diamantina, MG, Brasil.

\begin{abstract}
RESUMO: Foram realizados dois ensaios com o objetivo de avaliar o efeito da interferência de Brachiaria plantaginea (Link) Hitchc. , Amaranthus hybridus L. e Bidens pilosa L., bem como, a interferência do feijoeiro sobre o crescimento dessas plantas daninhas, além do efeito da mistura herbicida, fomesafen+fluazifop-p-butyl, sobre o desenvolvimento do feijoeiro. Os experimentos foram conduzidos em casa de vegetação, em vasos de $15 \mathrm{dm}^{3}$, utilizandose o delineamento em blocos casualizados. No primeiro experimento avaliou-se a interferência das plantas daninhas e o efeito da mistura herbicida sobre a cultura, já no segundo avaliou o efeito da interferência do feijoeiro no desenvolvimento das três espécies de plantas daninhas. A competição do feijoeiro com as plantas daninhas ocasionou efeitos negativos no crescimento da cultura, assim como, reduziu o crescimento das plantas infestantes. B. plantaginea e B. pilosa foram às espécies daninhas que mais acarretaram efeito negativo no crescimento da cultura. Todas as plantas infestantes tiveram o seu crescimento afetado negativamente quando em convivência com a cultura. A mistura herbicida ocasionou redução no crescimento radicular da cultura, podendo se refletir em futuras perdas de rendimento em condição de déficit hídrico ou escassez de nutrientes.
\end{abstract}

PALAVRAS-CHAVE: Bidens pilosa. Fomesafen+fluazifop-p-butyl. Habilidade competitiva. Interferência.

\section{INTRODUÇÃO}

O feijão-comum (Phaseolus vulgaris L.) é uma das culturas mais difundidas no Brasil, por constituir, juntamente com o arroz, alimento básico para a população. A área cultivada na safra 2012/2013 foi de, aproximadamente, 3,16 milhões de hectares, com produtividade média de $1050 \mathrm{~kg}$ $\mathrm{ha}^{-1}$ (CONAB, 2013), no entanto, em cultivos que empregam alto nível tecnológico a produtividade é cerca de três vezes maior a essa (SALGADO et al., 2007).

A baixa produtividade pode ser explicada, em parte, pelo manejo inadequado da comunidade infestante. O feijoeiro por apresentar crescimento inicial lento é muito susceptível a interferência de plantas daninhas, principalmente, no início do seu desenvolvimento. Segundo Kozlowski et al. (2002) a falta de controle da comunidade infestante pode acarretar em perdas de produtividade de até $71 \%$. Porém, a magnitude da competição interespecífica depende de fatores relacionados à comunidade infestante (densidade, distribuição e composição específica) e à própria cultura (gênero, espécie ou cultivar, espaçamento e densidade de plantio). Além disso, a duração do período de convivência entre plantas e a época em que a competição se estabelece, assim como, as condições edafoclimáticas e as técnicas de manejo adotadas, também influenciam na resposta das plantas a competição (PITELLI, 1985).

Diversos trabalhos têm avaliado a interferência de plantas daninhas na cultura do feijoeiro, porém as avaliações se restringem a redução no acúmulo de biomassa seca e produtividade (PARREIRA et al., 2012; BARROSO et al., 2012; SALGADO et al., 2007; TEIXEIRA et al., 2009). Entretanto, avaliações da interferência de plantas daninhas sobre o desenvolvimento da cultura, são de grande importância por possibilitar compreender a habilidade competitiva das espécies cultivada em relação as infestantes. Estudos que avaliam a competitividade da cultura com as plantas daninhas, permitem definir características que confiram maior habilidade competitiva as culturas (FLECK et al., 2006).

Atualmente, o principal método de manejo de plantas daninhas utilizados é o químico, através 
do uso de herbicidas tanto em pré quanto em pósemergência. Dentre os herbicidas comumente utilizados no feijoeiro, destaca-se a mistura comercial fomesafen+fluazifop-p-butyl. O fomesafen se caracteriza por ser um inibidor da PROTOX, controla grande número de folhas largas anuais e é recomendado para o uso em pósemergência das plantas daninhas na cultura do feijão. Fluazifop-p-butyl se caracteriza por ser inibidor da ACCase, classe de herbicida comumente recomendada para o controle de gramíneas em culturas dicotiledôneas, também, é recomendado a sua aplicação em pós-emergência da comunidade infestante na cultura do feijão. A associação destes ingredientes ativos permite o controle de algumas das principais infestantes na cultura. Porém, muitas vezes, a uso de herbicidas, mesmo sendo seletivos, pode acarretar em redução na taxa de crescimento da cultura, com reflexos negativos na sua produtividade (GALON et al., 2011).

Nem sempre o emprego de herbicidas sobre a cultura causam sintomas visuais de intoxicação, sendo que alguns produtos podem prejudicar o rendimento das culturas sem causar efeitos visualmente detectáveis (TORRES et al., 2012). No entanto, alguns herbicidas podem causar injúrias, que desaparecem com o desenvolvimento da cultura (NEGRISOLI et al., 2004).

Objetivou-se com este trabalho avaliar o efeito da interferência de Brachiaria plantaginea, Amaranthus hybridus e Bidens pilosa, comumente encontradas em lavouras de feijão, bem como, a interferência do feijoeiro sobre o desenvolvimento dessas plantas daninhas, além do efeito da mistura herbicida, fomesafen+fluazifop-p-butyl, sobre o desenvolvimento da cultura.

\section{MATERIAL E MÉTODOS}

O experimento foi conduzido em casa de vegetação, na Universidade Federal de Viçosa (UFV), Viçosa-MG. Foram realizados dois experimentos. O primeiro avaliou a interferência das plantas daninhas e o efeito da mistura herbicida sobre a cultura. $\mathrm{O}$ delineamento experimental utilizado foi de blocos ao acaso em esquema fatorial $(2 \mathrm{x}$ 5) com quatro repetições. $\mathrm{O}$ fator $\mathrm{A}$ correspondeu as épocas de avaliação: terceiro trifólio - V4 (35 dias após a emergência) e floração - R5 (60 dias após a emergência); e o fator B correspondeu ás espécies de plantas daninhas Brachiaria plantaginea (Link) Hitchc., Amaranthus hybridus L., Bidens pilosa L. em competição com feijoeiro, além do feijoeiro cultivado isoladamente e na presença da mistura comercial dos herbicidas fomesafen+fluazifop-p-butyl (Robust ${ }^{\circledR}$ ).

A aplicação da mistura comercial de herbicidas foi feita aos 25 dias após a emergência (DAE) da cultura, estando estas, no estádio V3, primeiro trifólio. Para aplicação do produto utilizouse um pulverizador costal pressurizado por gás carbônico, equipado com uma barra contendo uma ponta de pulverização da série TT 110.02, calibrado para aspergir $150 \mathrm{~L} \mathrm{ha}^{-1}$ de calda herbicida.

$\mathrm{O}$ segundo experimento avaliou o efeito da interferência do feijoeiro no desenvolvimento das três espécies de plantas daninhas. Os dados foram transformados em porcentagem em relação à testemunha (planta daninha cultivada isoladamente). $\mathrm{O}$ delineamento utilizado foi o de blocos ao acaso com quatro repetições em esquema fatorial $3 \times 2$, onde $\mathrm{o}$ fator $\mathrm{A}$ corresponde as três espécies de plantas daninhas e o fator B as épocas de avaliação, terceiro trifólio - V4 (35 dias após a emergência) e floração - R5 (60 dias após a emergência).

As unidades experimentais foram constituídas por vasos com $15 \mathrm{dm}^{3}$ de substrato (solo + fertilizantes). Como substrato utilizou-se Latossolo Vermelho-Amarelo, previamente corrigido e adubado. De acordo com a análise realizada, o solo apresentou as seguintes características: $\mathrm{pH}$ em água de 4,3; $\mathrm{MO}=2,5 \mathrm{dag} \mathrm{kg}^{-}$ ;; $\quad \mathrm{P}=1,5 \mathrm{mg} \mathrm{dm}^{-3} ; \quad \mathrm{K}=40 \mathrm{mg} \mathrm{dm}^{-3}$; $\mathrm{Al}^{3+}=0,5 \mathrm{cmol}_{\mathrm{c}} \mathrm{dm}^{-3} ; \quad \mathrm{Ca}^{2+}=1,3 \mathrm{cmol}_{\mathrm{c}} \mathrm{dm}^{-3}$; $\mathrm{Mg}^{2+}=0,2 \mathrm{cmol}_{\mathrm{c}} \mathrm{dm}^{-3} ; \quad \mathrm{CTC}(\mathrm{t})=2,1 \mathrm{cmol}_{\mathrm{c}} \mathrm{dm}^{-3}$; CTC(T)=6,39 $\mathrm{cmol}_{\mathrm{c}} \mathrm{dm}^{-3} ; \mathrm{H}+\mathrm{Al}=4,79 \mathrm{cmol}_{\mathrm{c}} \mathrm{dm}^{-3}$; $\mathrm{SB}=1,6 \mathrm{cmol}_{\mathrm{c}} \mathrm{dm}^{-3} ; \mathrm{V}=25 \% ;$ e argila $=38 \%$. A adubação do solo foi de $20 \mathrm{~g}$ de cloreto de sódio, $500 \mathrm{~g}$ de superfosfato simples, $50 \mathrm{~g}$ de sulfato de amônio e $150 \mathrm{~g}$ de calcário dolomítico, de acordo com recomendação de Cantarutti et al. (2007) para adubação em vaso.

Foi utilizado sementes de feijoeiro comum, cultivar BRS Supremo. Trata-se de um cultivar de grão preto de porte ereto, crescimento indeterminado, com número médio de dias para a floração de 39 dias e com ciclo médio de 83 dias da emergência até a maturação (EMBRAPA, 2004; CARVALHO; ALBRECHT, 2007). As sementes de feijoeiro foram alocadas no centro do vaso (uma planta por vaso) e as plantas daninhas foram semeadas na periferia do vaso (duas plantas por vaso) na densidade de 130 plantas $\mathrm{m}^{-2}$.

As avaliações foram realizadas aos 35 e 60 DAE da cultura. No momento das avaliações foi determinado o diâmetro da haste do feijoeiro (DH$\mathrm{mm}$ ) e após a medição, foi realizada a colheita das plantas. As plantas de feijão foram separadas em caule, folhas e raízes e logo após a separação das folhas, a área foliar da cultura foi determinada (AF- 
$\mathrm{cm}^{2}$ ). As amostras coletadas foram acondicionadas em sacos de papel e levadas para a estufa de circulação forçada de ar a temperatura de $70^{\circ} \mathrm{C}$ até massa constante, neste momento foi determinada a massa da matéria seca das folhas (MSF-g), do caule (MSC-g), das raízes (MSR-g) das plantas daninhas e do feijoeiro. A partir destas variáveis foram calculadas a massa da matéria seca total (MST-g = MSF+MSC+MSR); taxa de crescimento da cultura (TCC $=$ MST/Dias até a colheita para cada época de avaliação) e relação parte aérea raízes $(\mathrm{Pa} / \mathrm{Rz}=$ MSC+MSF/MSR).

Para a avaliação do efeito da competição do feijoeiro nas três espécies de plantas daninhas os dados foram transformados em porcentagem em relação à testemunha gerando as variáveis porcentagens de massa da matéria seca das folhas, raízes, caule e total (MSF\%, MSC\%, MSR\% e MST\%), além da porcentagem da taxa de crescimento da cultura (TCC\%).

Todos os dados foram submetidos à análise de variância. Efetuou-se o desdobramento da interação significativa, empregando-se o teste Tukey a 5\% de probabilidade de erro para as comparações entre espécies competidoras e época de avaliações. Para as interações não significativas, o efeito da competição no feijoeiro e nas plantas daninhas foi avaliado entre as espécies.

\section{RESULTADOS E DISCUSSÃO}

A interação entre espécies de plantas daninhas e épocas de avaliação foi significativa $(\mathrm{P}<0,05)$ para a matéria seca das folhas, raízes, matéria seca total, taxa de crescimento da cultura, relação parte aérea raízes, diâmetro da haste, área foliar e área foliar específica do feijoeiro. Realizouse o desdobramento dessas interações avaliando-se apenas o efeito de espécie, dentro de cada época de colheita.

O acúmulo de massa da matéria seca das folhas (MSF) do feijoeiro foi pouco afetado pela convivência com as plantas daninhas, tanto aos 35 quanto aos 60 DAE. As plantas de feijoeiro em convivência com Brachiaria plantaginea e Bidens pilosa aos 60 DAE apresentaram os menores valores de MSF, diferindo do tratamento onde essa cultura foi submetida à aplicação da mistura de herbicidas fomesafen+fluazifop-p-butyl, porém, sem diferir, das plantas de feijão cultivadas isoladamente (Tabela 1). B. plantaginea $e$ B. pilosa se caracterizam por serem espécies infestantes com rápido crescimento inicial e serem altamente competitivas na captação dos recursos do meio. A alta capacidade competitiva dessas espécies daninhas pode ter contribuído para a redução da alocação de biomassa para a formação das folhas. Apesar da redução no acumulo de biomassa nas folhas ocasionada por esses dois tratamentos a área foliar (AF) da cultura não foi afetada aos 60 DAE, sendo que, observou-se apenas redução inicial da AF, aos 35 DAE, quando em convivência com $A$. hybridus e B. pilosa, com posterior recuperação da cultura (Tabela 2).

Não houve interação significativa entre as espécies de plantas daninhas e épocas de avaliação para a matéria seca do caule (MSC) do feijoeiro. $B$. pilosa foi o tratamento que ocasionou menor valor de MSC quando em comparação aos tratamentos nos quais o feijão cresceu no limpo e na presença do herbicida (Tabela 3 ).

Tabela 1. Massa da matéria seca das folhas (MSF - g) de plantas de feijoeiro submetida à competição com plantas daninhas. Viçosa - MG, 2012.

\begin{tabular}{lcc}
\hline \multirow{2}{*}{ Tratamentos } & $3^{\circ}$ Trifólio (Estádio V4) & Floração (Estádio R6) \\
& 35 DAE & 60 DAE \\
\hline Feijão & $3,89 \mathrm{~b}$ & $20,28 \mathrm{ab}$ \\
Feijão+Herbicida & $7,39 \mathrm{ab}$ & $21,37 \mathrm{a}$ \\
Feijão+ Amaranthus hybridus & $9,67 \mathrm{a}$ & $17,60 \mathrm{ab}$ \\
Feijão+Bidens pilosa & $4,45 \mathrm{ab}$ & $14,83 \mathrm{~b}$ \\
Feijão+Brachiaria plantaginea & $4,26 \mathrm{~b}$ & $14,94 \mathrm{~b}$ \\
\hline F (Espécies) & $5,81^{* *}$ \\
F (Época de avaliação) & $207,78^{* *}$ \\
F (Interação) & $3,18^{*}$ \\
DMS & 5,39 \\
CV $(\%)$ & \multicolumn{3}{|}{21,96} \\
\hline
\end{tabular}

Médias seguidas pela mesma letra minúscula na coluna não diferem entre si pelo Teste de Tukey a 5\% de probabilidade. *significativo em nível de $5 \%$ de probabilidade, **significativo em nível de $1 \%$ de probabilidade. 
Tabela 2. Área Foliar $\left(\mathrm{AF}-\mathrm{cm}^{2}\right)$ de plantas de feijoeiro submetida à competição com plantas daninhas. Viçosa $-\mathrm{MG}, 2012$.

\begin{tabular}{lcc}
\hline \multirow{2}{*}{ Tratamentos } & $3^{\text {o }}$ Trifólio (Estádio V4) & Floração (Estádio R6) \\
& 35 DAE & $118,20 \mathrm{a}$ \\
Feijão & $117,75 \mathrm{a}$ & $108,27 \mathrm{a}$ \\
Feijão+Herbicida & $121,50 \mathrm{a}$ & $130,37 \mathrm{a}$ \\
Feijão+Amaranthus hybridus & $66,90 \mathrm{~b}$ & $101,12 \mathrm{a}$ \\
Feijão+Bidens pilosa & $92,12 \mathrm{~b}$ & $96.94 \mathrm{a}$ \\
Feijão+Brachiaria plantaginea & $111,45 \mathrm{a}$ & \\
\hline F (Espécies) & $2,37^{\mathrm{ns}}$ \\
F (Época de avaliação) & $2,64^{\mathrm{ns}}$ \\
F (Interação) & $6,63^{* *}$ \\
DMS & 36,28 \\
CV (\%) & \multicolumn{3}{|}{} \\
\hline
\end{tabular}

Médias seguidas pela mesma letra minúscula na coluna não diferem entre si pelo Teste de Tukey a $5 \%$ de probabilidade. **significativo em nível de $1 \%$ de probabilidade, ${ }^{\text {ns }}$ em significativo.

Tabela 3. Massa da matéria seca do caule (MSC - g) de plantas de feijoeiro submetida à competição com plantas daninhas. Viçosa - MG, 2012.

\begin{tabular}{lc}
\hline Tratamentos & MSC \\
\hline Feijão & $11,02 \mathrm{a}$ \\
Feijão+Herbicida & $11,28 \mathrm{a}$ \\
Feijão+ Amaranthus hybridus & $9,75 \mathrm{ab}$ \\
Feijão+Bidens pilosa & $7,33 \mathrm{~b}$ \\
Feijão+Brachiaria plantaginea & $8,82 \mathrm{ab}$ \\
\hline F (Espécies) & $6,08^{* *}$ \\
F (Época de avaliação) & $1,96^{\mathrm{ns}}$ \\
F (Interação) & $0,73^{\mathrm{ns}}$ \\
DMS & 3,85 \\
CV $(\%)$ & 19,36
\end{tabular}

Médias seguidas pela mesma letra minúscula na coluna não diferem entre si pelo Teste de Tukey a 5\% de probabilidade. **significativo em nível de $1 \%$ de probabilidade, ${ }^{\text {ns }}$ não significativo.

Comportamento diferente foi observado para o diâmetro da haste $(\mathrm{DH})$ da cultura, em que inicialmente, o DH foi afetado, negativamente, pela interferência com Brachiaria plantaginea, porém aos 60 DAE não houve diferença entre os tratamentos (Tabela 4).

A massa de matéria seca das raízes (MSR) do feijoeiro não foi afetada pelos tratamentos aos 35 DAE. Por outro lado, aos 60 DAE as plantas de feijão que cresceram na convivência das plantas daninhas apresentaram os menores valores, seguido pelo tratamento submetido a mistura herbicida (Tabela 5). O baixo acúmulo de MSR da cultura pode implicar em menor tolerância ao déficit hídrico e consequentemente menor produtividade. Cury et al. (2011) observaram que a cultivar de feijão Perola sob interferência de plantas daninhas, apresentou menor alocação relativa de matéria seca nas raízes em relação a testemunha. De acordo com os autores, o potencial agressivo das infestantes, frente a cultivar, em nível radicular fez com que o feijoeiro induzisse maior alocação de matéria seca nos órgãos superiores. É importante notar que a mistura herbicida, também, ocasionou redução na MSR quando comparada com a testemunha, indicando possível efeito fitotóxico da molécula aos 60 DAE. 
Tabela 4. Diâmetro da haste $(\mathrm{DH}$ - $\mathrm{mm})$ de plantas de feijoeiro submetida à competição com plantas daninhas. Viçosa - MG, 2012.

\begin{tabular}{lcc}
\hline Tratamentos & $3^{\circ}$ Trifólio (Estádio V4) & Floração (Estádio R6) \\
35 DAE DAE \\
\hline Feijão & $0,89 \mathrm{a}$ & $0,86 \mathrm{a}$ \\
Feijão+Herbicida & $0,98 \mathrm{a}$ & $0,91 \mathrm{a}$ \\
Feijão+Amaranthus hybridus & $0,44 \mathrm{ab}$ & $0,95 \mathrm{a}$ \\
Feijão+Bidens pilosa & $0,54 \mathrm{ab}$ & $0,84 \mathrm{a}$ \\
Feijão+Brachiaria plantaginea & $0,27 \mathrm{~b}$ & $0,91 \mathrm{a}$ \\
\hline F (Espécies) & $10,73^{* *}$ \\
F (Época de avaliação) & $45,92^{* *}$ \\
F (Interação) & $12,69^{* *}$ \\
DMS & 0,26 \\
CV $(\%)$ & \multicolumn{3}{c}{16,55} \\
\hline
\end{tabular}

Médias seguidas pela mesma letra minúscula na coluna não diferem entre si pelo Teste de Tukey a 5\% de probabilidade. **significativo em nível de $1 \%$ de probabilidade.

Tabela 5. Massa da matéria seca das raízes (MSR - g) de plantas de feijoeiro submetida à competição com plantas daninhas. Viçosa - MG, 2012.

\begin{tabular}{lcc}
\hline Tratamentos & $\begin{array}{c}3^{\circ} \text { Trifólio (Estádio V4) } \\
\text { 35 DAE }\end{array}$ & $\begin{array}{c}\text { Floração (Estádio R6) } \\
60 \text { DAE }\end{array}$ \\
\hline Feijão & $3,22 \mathrm{a}$ & $12,25 \mathrm{a}$ \\
Feijão+Herbicida & $4,16 \mathrm{a}$ & $8,28 \mathrm{~b}$ \\
Feijão+ Amaranthus hybridus & $2,96 \mathrm{a}$ & $5,39 \mathrm{c}$ \\
Feijão+Bidens pilosa & $1,64 \mathrm{a}$ & $3,47 \mathrm{c}$ \\
Feijão+Brachiaria plantaginea & $2,77 \mathrm{a}$ & $2,86 \mathrm{c}$ \\
\hline F (Espécies) & $23,69^{* *}$ \\
F (Época de avaliação) & $72,63^{* *}$ \\
F (Interação) & $13,79^{* *}$ \\
DMS & 2,68 \\
CV (\%) & \multicolumn{3}{|}{27,60} \\
\hline
\end{tabular}

Médias seguidas pela mesma letra minúscula na coluna não diferem entre si pelo Teste de Tukey a 5\% de probabilidade. **significativo em nível de $1 \%$ de probabilidade.

Com relação ao acúmulo de massa da matéria seca total (MST), a convivência das plantas de feijão com $B$. pilosa e B. plantaginea foram os tratamentos que ocasionaram maior redução desta variável aos 35 e 60 DAE. A. hybridus foi a espécie daninha que menos afetou a MST do feijoeiro (Tabela 6). O baixo acúmulo da MST pode ser explicado pelo menor acúmulo de matéria seca nas folhas e raízes ocasionadas pela convivência da cultura com B. pilosa e B. plantaginea. Apesar de A. hybridus não ter ocasionado redução no acúmulo da MST, geralmente, em condições de campo essa espécie infestante pode ocorrer em alta densidade, podendo ocasionar perdas significativas no rendimento da cultura.

Aos 35 DAE não foram observadas diferença entre os tratamentos, para a relação parte aérea raízes $(\mathrm{Pa} / \mathrm{Rz})$ do feijoeiro, porém com o aumento do período de convivência da cultura com as plantas daninhas, observou-se baixa relação $\mathrm{Pa} / \mathrm{Rz}$, aos $60 \mathrm{DAE}$ para a testemunha e para o tratamento com herbicida indicando que a cultura, quando livre de infestação, investiu maior acúmulo de biomassa no sistema radicular. No entanto, na presença de plantas daninhas, em especial com $B$. plantaginea, houve inversão dessa relação, ou seja, o feijoeiro privilegiou o incremento da parte aérea em detrimento do sistema radicular (Tabela 7).

$\mathrm{O}$ fato de a cultura destinar maior alocação de biomassa para a parte aérea, principalmente para as folhas, pode indicar uma tentativa de o feijoeiro reduzir a radiação incidente sob as espécies com as quais estava convivendo, visando reduzir o crescimento das plantas daninhas. As plantas quando privadas de quaisquer fatores necessários ao seu crescimento, tendem a alterar o seu padrão de distribuição de fotoassimilados e, como consequência, de suas características morfológicas 
(CURY et al., 2011).

Tabela 6. Massa da matéria seca total (MST - g) de plantas de feijoeiro submetida à competição com plantas daninhas. Viçosa - MG, 2012.

\begin{tabular}{lcc}
\hline \multirow{2}{*}{ Tratamentos } & $3^{\circ}$ Trifólio (Estádio V4) & Floração (Estádio R6) \\
& 35 DAE & 60 DAE \\
\hline Feijão & $18,47 \mathrm{a}$ & $43,21 \mathrm{a}$ \\
Feijão+Herbicida & $22,71 \mathrm{a}$ & $41,07 \mathrm{ab}$ \\
Feijão+Amaranthus hybridus & $21,90 \mathrm{a}$ & $33,33 \mathrm{bc}$ \\
Feijão+Bidens pilosa & $12,24 \mathrm{~b}$ & $26,82 \mathrm{c}$ \\
Feijão+Brachiaria plantaginea & $15,24 \mathrm{~b}$ & $27,23 \mathrm{c}$ \\
\hline F (Espécies) & $13,18^{* *}$ \\
F (Época de avaliação) & $138,69^{* *}$ \\
F (Interação) & $3,18^{*}$ \\
DMS & \multicolumn{3}{c}{} \\
CV $(\%)$ & \multicolumn{3}{c}{26,22} \\
\hline
\end{tabular}

Médias seguidas pela mesma letra minúscula na coluna não diferem entre si pelo Teste de Tukey a 5\% de probabilidade. *significativo em nível de $5 \%$ de probabilidade, **significativo em nível de $1 \%$ de probabilidade.

Tabela 7. Relação parte aérea raízes $(\mathrm{Pa} / \mathrm{Rz})$ de plantas de feijoeiro submetida à competição com plantas daninhas. Viçosa - MG, 2012.

\begin{tabular}{lcc}
\hline Tratamentos & $3^{\text {o }}$ Trifólio (Estádio V4) & Floração (Estádio R6) \\
& 35 DAE & 60 DAE \\
\hline Feijão & $4,72 \mathrm{a}$ & $2,59 \mathrm{~b}$ \\
Feijão+Herbicida & $4,71 \mathrm{a}$ & $4,08 \mathrm{~b}$ \\
Feijão+Amaranthus hybridus & $6,80 \mathrm{a}$ & $5,71 \mathrm{ab}$ \\
Feijão+Bidens pilosa & $7,04 \mathrm{ab}$ \\
Feijão+Brachiaria plantaginea & $7,74 \mathrm{a}$ & $8,78 \mathrm{a}$ \\
\hline F (Espécies) & $5,08 \mathrm{a}$ & \\
F (Época de avaliação) & $9,06^{* *}$ \\
F (Interação) & $0,13^{\text {ns }}$ \\
DMS & $4,34^{* *}$ \\
CV $(\%)$ & 3,15 \\
\hline
\end{tabular}

Médias seguidas pela mesma letra minúscula na coluna não diferem entre si pelo Teste de Tukey a 5\% de probabilidade. ${ }^{* *}$ significativo em nível de $1 \%$ de probabilidade, ${ }^{\text {ns }}$ não significativo.

Os tratamentos não alteraram a taxa de crescimento da cultura (TCC), aos 35 DAE, porém, aos 60 DAE observou-se que $B$. pilosa e $B$. plantaginea ocasionaram redução na TCC (Tabela 8). Ambas as espécies daninhas se caracterizam por serem de ampla distribuição nacional e muito competitiva, principalmente, com culturas anuais podendo provocar prejuízos consideráveis ao rendimento e qualidade da produção (SANTOS; CURY, 2011). A baixa TCC observada aos 60 DAE quando em convivência com as plantas daninhas demonstra que, geralmente, as plantas cultivadas, têm menor capacidade competitiva, em razão do processo de melhoramento pelo qual passaram, do que espécies da comunidade infestante (plantas não cultivadas); como consequência, apresentam menor tolerância aos efeitos da competição (FONTES et al., 2003).

Para o efeito da interferência do feijoeiro no desenvolvimento das espécies de plantas daninhas, observou-se que a interação entre espécies de plantas daninhas e épocas de avaliação foi significativa $(\mathrm{P}<0,05)$ para a porcentagem de matéria seca das folhas e das raízes das plantas daninhas.

Analisando o efeito da cultura sob a porcentagem de massa da matéria seca das folhas (MSF\%) das plantas daninhas em relação a testemunha (planta daninha cultivada isoladamente) observou-se que, inicialmente, as plantas de $A$. hybridus foram as que menos sofreram interferência do feijoeiro, porém aos 60 DAE o comportamento se inverteu, ou seja, A. hybridus foi a espécie que 
teve a maior redução de MSF\%, aproximadamente, $70 \%$ e B. pilosa foi a espécie menos afetada com redução, próxima, de 38\% (Tabela 9).

Tabela 8. Taxa de crescimento da cultura (TCC) de plantas de feijoeiro submetida à competição com plantas daninhas. Viçosa - MG, 2012.

\begin{tabular}{lcc}
\hline Tratamentos & $3^{\circ}$ Trifólio (Estádio V4) & Floração (Estádio R6) \\
\hline Feijão & 35 DAE & 60 DAE \\
Feijão+Herbicida & $1,31 \mathrm{a}$ & $0,96 \mathrm{a}$ \\
Feijão+Amaranthus hybridus & $1,38 \mathrm{a}$ & $0,91 \mathrm{ab}$ \\
Feijão+Bidens pilosa & $1,36 \mathrm{a}$ & $0,74 \mathrm{bc}$ \\
Feijão+Brachiaria plantaginea & $1,20 \mathrm{a}$ & $0,59 \mathrm{c}$ \\
\hline
\end{tabular}

\begin{tabular}{lc}
\hline F (Espécies) & $13,63^{* *}$ \\
F (Época de avaliação) & $281,44^{* *}$ \\
F (Interação) & $4,41^{* *}$ \\
DMS & 0,17 \\
CV $(\%)$ & 19,22
\end{tabular}

Médias seguidas pela mesma letra minúscula na coluna não diferem entre si pelo Teste de Tukey a $5 \%$ de probabilidade. ${ }^{* *}$ significativo em nível de $1 \%$ de probabilidade.

Tabela 9. Porcentagem de massa da matéria seca das folhas (MSF\%) de plantas de daninhas em competição com plantas de feijoeiro. Viçosa - MG, 2012.

\begin{tabular}{lcc}
\hline Tratamentos & $\begin{array}{c}3^{\circ} \text { Trifólio (Estádio V4) } \\
\text { 35 DAE }\end{array}$ & $\begin{array}{c}\text { Floração (Estádio R6) } \\
60 \text { DAE }\end{array}$ \\
\hline Feijão+Amaranthus hybridus & $63,00 \mathrm{a} \mathrm{A}$ & $30,61 \mathrm{~b} \mathrm{~B}$ \\
Feijão+Bidens pilosa & $37,76 \mathrm{~b} \mathrm{~B}$ & $62,17 \mathrm{a} \mathrm{A}$ \\
Feijão+Brachiaria plantaginea & $44,17 \mathrm{~b} \mathrm{~A}$ & $46,06 \mathrm{ab}$ A \\
\hline F (Espécies) & $0,63^{\text {ns }}$ \\
F (Época de avaliação) & $0,32^{\text {ns }}$ \\
F (Interação) & $21,25^{* *}$ \\
DMS (Espécies) & 16,12 \\
DMS (Época de avaliação) & 13,22 \\
CV (\%) & 18,55 \\
\hline
\end{tabular}

Médias seguidas pela mesma letra minúscula na coluna e maiúscula na linha não diferem entre si pelo Teste de Tukey a 5\% de probabilidade. $* *$ significativo em nível de $1 \%$ de probabilidade, ${ }^{\text {ns }}$ não significativo.

Não houve efeito da interação entre espécies de plantas daninhas e épocas de avaliação para a porcentagem de massa da matéria seca do caule (MSC\%), massa da matéria seca total (MST\%) e taxa de crescimento (TC\%) das plantas daninhas em relação à testemunha.

Para a porcentagem de massa da matéria seca do caule das plantas daninhas em relação à testemunha (MSC\%) verificou-se efeito dos tratamentos, sendo que as espécies $A$. hybridus e $B$. plantaginea apresentaram as maiores perdas de porcentagem de matéria seca, correspondente a, aproximadamente, 66 e $65 \%$ respectivamente, enquanto para $B$. pilosa esta perda foi de cerca de $40 \%$ (Tabela 10).

A porcentagem de massa da matéria seca das raízes (MSR\%) das plantas daninhas $A$. hybridus, B. pilosa e B. plantaginea na primeira avaliação apresentou redução de aproximadamente 85,65 e $40 \%$, respectivamente, em relação às plantas daninhas cultivadas isoladamente. $\mathrm{Na}$ segunda época estes valores foram 60, 80 e $50 \%$ para as mesmas espécies, respectivamente. Ao avaliar as épocas observou-se que A. hybridus foi mais afetada no estádio V4 e B. plantaginea na segunda época. A baixa quantidade de alocação de biomassa para o sistema radicular de B. pilosa quando em competição com a cultura, pode ser atribuída a uma realocação dos fotoassimilados para a parte aérea, visando maior captação de energia luminosa, como forma de sombrear a planta concorrente e se sobressair (Tabela 11). A redução do sistema radicular das plantas daninhas pode implicar em menor absorção e menor capacidade de 
competição de nutrientes devido a menor exploração

do solo pelas raízes.

Tabela 10. Porcentagem de massa da matéria seca do caule (MSC\%) de plantas de daninhas em competição com plantas de feijoeiro. Viçosa - MG, 2012.

\begin{tabular}{lc} 
Tratamentos & MSC\% \\
\hline Feijão+Amaranthus hybridus & $33,96 \mathrm{~b}$ \\
Feijão+Bidens pilosa & $59,28 \mathrm{a}$ \\
Feijão+Brachiaria plantaginea & $34,93 \mathrm{~b}$ \\
\hline F (Espécies) & $29,76^{* *}$ \\
F (Época de avaliação) & $19,77^{* *}$ \\
F (Interação) & $0,25^{\mathrm{ns}}$ \\
DMS & 9,66 \\
CV (\%) & 17,41 \\
\hline
\end{tabular}

Médias seguidas pela mesma letra minúscula na coluna e maiúscula na linha não diferem entre si pelo Teste de Tukey a 5\% de probabilidade. $* *$ significativo em nível de $1 \%$ de probabilidade, ${ }^{\text {ns }}$ não significativo.

Tabela 11. Porcentagem de massa da matéria seca das raízes (MSR\%) de plantas de daninhas em competição com plantas de feijoeiro. Viçosa - MG, 2012.

\begin{tabular}{lcc}
\hline Tratamentos & $\begin{array}{c}3^{\circ} \text { Trifólio (Estádio V4) } \\
\text { 35 DAE }\end{array}$ & $\begin{array}{c}\text { Floração (Estádio R6) } \\
60 \text { DAE }\end{array}$ \\
\hline Feijão+Amaranthus hybridus & $24,28 \mathrm{~b} \mathrm{~B}$ & 43,24 a A \\
Feijão+Bidens pilosa & $34,36 \mathrm{~b} \mathrm{~A}$ & $21,41 \mathrm{~b} \mathrm{~A}$ \\
Feijão+Brachiaria plantaginea & $61,10 \mathrm{a} \mathrm{A}$ & $47,93 \mathrm{a} \mathrm{B}$ \\
\hline F (Espécies) & $25,85^{* *}$ \\
F (Época de avaliação) & $0,56^{\mathrm{ns}}$ \\
F (Interação) & $11,28^{* *}$ \\
DMS (Espécies) & 14,30 \\
DMS (Época de avaliação) & 11,72 \\
CV (\%) & 20,10 \\
\hline
\end{tabular}

Médias seguidas pela mesma letra minúscula na coluna e maiúscula na linha não diferem entre si pelo Teste de Tukey a 5\% de probabilidade. **significativo em nível de $1 \%$ de probabilidade, ${ }^{\text {ns }}$ não significativo.

Com relação a porcentagem de massa da matéria seca total (MST\%) das plantas daninhas, observou-se que $A$. hybridus, foi a espécie infestante mais sensível a convivência com o feijoeiro, apresentando redução de, aproximadamente, $67 \%$ em relação à testemunha, já com relação à $B$. pilosa e B. plantaginea estas perdas foram da ordem de cerca de 49 e $55 \%$ respectivamente (Tabela 12). Os resultados estão de acordo com os encontrados por Silva et al (2006), onde os autores observaram que o feijoeiro foi capaz de reduzir o acúmulo da massa de matéria seca de B. brizantha em 50\%, quando comparada com a braquiária plantada em monocultivo.
A porcentagem de taxa de crescimento das plantas daninhas (TC\%) foi afetada de maneira significativa. A. hybridus foi a espécie infestante que apresentou maior redução na TC\%, cerca de, $62 \%$ inferior a sua testemunha (Tabela 13). Esses resultados indicam que apesar das plantas daninhas terem afetado negativamente o crescimento da cultura, elas, também, tiveram o seu crescimento reduzido. Nas áreas agrícolas, as plantas daninhas por serem espécies não cultivadas e ocorrerem, em geral, em populações superiores às das plantas cultivadas são freqüentemente rotuladas como mais competitivas (BIANCHI et al., 2006). 
Tabela 12. Porcentagem de massa da matéria seca total (MST\%) de plantas daninhas em competição com plantas de feijoeiro. Viçosa - MG, 2012.

Tratamentos

MST\%

Feijão+Amaranthus hybridus

$32,88 \mathrm{~b}$

Feijão+Bidens pilosa

51,23 a

Feijão+Brachiaria plantaginea

45,37 a

F (Espécies)

$21,16^{* *}$

F (Época de avaliação)

$9,06^{* *}$

$\mathrm{F}$ (Interação)

$0,42^{\text {ns }}$

DMS (Espécies)

7,49

DMS (Época de avaliação)

5,01

$\mathrm{CV}(\%)$

13,35

Médias seguidas pela mesma letra minúscula na coluna não diferem entre si pelo Teste de Tukey a 5\% de probabilidade. **significativo em nível de $1 \%$ de probabilidade, ${ }^{\text {ns }}$ não significativo.

Tabela 13. Porcentagem de taxa de crescimento da cultura (TC\%) de plantas de daninhas em competição com plantas de feijoeiro. Viçosa - MG, 2012.

\begin{tabular}{lc}
\hline Tratamentos & TC\% \\
\hline Feijão+Amaranthus hybridus & $38,10 \mathrm{~b}$ \\
Feijão+Bidens pilosa & $53,14 \mathrm{a}$ \\
Feijão+Brachiaria plantaginea & $43,80 \mathrm{ab}$ \\
\hline F (Espécies) & $6,19^{*}$ \\
F (Época de avaliação) & $4,31^{\mathrm{ns}}$ \\
F (Interação) & $0,14^{\mathrm{ns}}$ \\
DMS & 11,21 \\
CV $(\%)$ & 19,17 \\
\hline
\end{tabular}

Médias seguidas pela mesma letra minúscula na coluna e maiúscula na linha não diferem entre si pelo Teste de Tukey a $5 \%$ de probabilidade. *significativo em nível de $5 \%$ de probabilidade, ${ }^{\text {ns }}$ não significativo.

\section{CONCLUSÕES}

A competição do feijoeiro com as plantas daninhas, reduz o crescimento da cultura, assim como, diminuiu o crescimento das plantas infestantes.

As espécies Brachiaria plantaginea e Bidens pilosa foram as daninhas que mais acarretaram em efeito negativo no crescimento da cultura. Todas as plantas infestantes tiveram o seu crescimento afetado negativamente quando em convivência com a cultura.

A mistura de herbicidas fomesafen+fluazifop-p-butyl reduz o crescimento do sistema radicular do feijoeiro, podendo acarretar em futuras perdas de rendimento dessa cultura, principalmente em condição de déficit hídrico ou escassez de nutrientes.

\section{AGRADECIMENTOS}

Os autores agradecem a Coordenação de Aperfeiçoamento de Pessoal de Nível Superior (CAPES) e ao Conselho Nacional de Desenvolvimento Científico e Tecnológico (CNPq) pelo apoio financeiro e as bolsas concedidas.

\footnotetext{
ABSTRACT: The objective of this work was to evaluate the effect of interference Brachiaria plantaginea, Bidens pilosa and Amaranthus hybridus in the growth of bean plants, as well as the interference of bean on the growth of these weeds, plus the effect of the herbicide mixture, fomesafen + fluazifop-p-butyl, on the development of bean. The experiments were conducted in a greenhouse in pots of $15 \mathrm{dm}^{3}$, using a randomized block design. The first experiment evaluated the effect of weed and the effect of the herbicide mixture on the culture, in the second evaluated the effect of
} 
interference of bean in the development of three weed species. The bean competition with weeds caused negative effects on crop growth as well as reduced the growth of weeds. B. plantaginea and B. pilosa were the weeds that have resulted in more negative effect on crop growth. All weeds had negative affected growth of the culture. The herbicide mixture caused reduction in root growth of culture; this fact may be reflected in future income losses in water stress conditions or lack of nutrients.

KEYWORDS: Bidens pilosa. Competitive ability. Fomesafen+fluazifop-p-butyl. Interference.

\section{REFERÊNCIAS}

BARROSO, A. A. M.; YAMAUTI, M. S.; NEPOMUCENO, M. P.; ALVES, P. L. C. A. Efeito da densidade e da distância de caruru-de-mancha e amendoim-bravo na cultura do feijoeiro. Planta daninha, Viçosa, v. 30, n. 1, p. 47-53, 2012.

BIANCHI, M. A.; FLECK, N. G.; LAMEGO, F. P. Proporção entre plantas de soja e plantas competidoras e as relações de interferência mútua. Ciência Rural, Santa Maria, v. 36, n. 3, p. 1380-1387, 2006.

http://dx.doi.org/10.1590/S0103-84782006000500006

CANTARUTTI, R. B.; BARROS, N. F. de.; PRIETO, H. E.; NOVAIS, R. F. Avaliação da fertilidade do solo e recomendação de fertilizantes. In: NOVAIS, R. F.; ALVAREZ V.; V. H.; BARROS, N. F. de.; FONTES, R. L. F.; CANTARUTTI, R. B.; NEVES, J. C. L. Fertilidade do solo. Viçosa: Sociedade Brasileira da Ciência do Solo, 2007. p. 769-850.

CARVALHO, W. P. de.; ALBRECHT, J. C. BRS Supremo: cultivar de grão preto de feijoeiro de porte ereto indicada para a região do Distrito Federal. Planaltina: Embrapa Cerrados, 2007. 2 p. Comunicado técnico, 137.

CONAB. Acompanhamento da safra brasileira: grãos, quarto levantamento safra 2012/2013. Brasília:

Conab, Jan. 2013. Disponível em:

$<$ http://www.conab.gov.br/OlalaCMS/uploads/arquivos/13_01_09_17_44_20_boletim_graos_janeiro_2013.pdf >. Acesso em: 12 mar. 2013.

CURY, J. P.; SANTOS, J. B.; VALADÃO SILVA, D.; CARVALHO, F. P.; BRAGA, R. R.; BYRRO, E. C. M.; FERREIRA, E. A. Produção e partição de matéria seca de cultivares de feijão em competição com plantas daninhas. Planta Daninha, Viçosa, v. 29, n. 1, p. 149-158, 2011.

EMBRAPA. Cultivar de feijoeiro comum BRS Supremo: grupo comercial preto, porte ereto. Santo Antônio de Goiás: Embrapa Arroz e Feijão, 2004, 2 p. Disponível em:

http://www.infoteca.cnptia.embrapa.br/bitstream/doc/216229/1/FD2004.008.pdf. Acesso em: 09 de maio de 2014.

FLECK, N. G.; BIANCHI, M. A.; RIZZARDI, M. A.; AGOSTINETTO, D. Interferência de Raphanus sativus sobre cultivares de soja durante a fase vegetativa de desenvolvimento da cultura. Planta Daninha, Viçosa, v. 24, n. 3, p. 425-434, 2006.

FONTES, J. R. A.; SHIRATSUCHI, L. S.; NEVES, J. L.; JÚLIO, L. de.; SONDRÉ FILHO, J. Manejo integrado de plantas daninhas. Planaltina: Embrapa-CPAC, 2003. 48 p. Boletim Técnico, 103.

GALON, L.; AGOSTINETTO, D.; MORAES, P. V. D.; DAL MAGRO, T.; PANOZZO, L. E.; BRANDOLT, R. R.; SANTOS, L. S.; Níveis de dano econômico para decisão de controle de capim-arroz (Echinochloa spp.) em arroz irrigado (Oryza sativa). Planta Daninha, Viçosa, v. 25, n. 4, p.709-718, 2007.

KOZLOWSKI, L. A.; RONZELLI JÚNIOR, P.; PURISSIMO, C.; DAROS, E.; KOEHLER, H. S. Período crítico de interferência das plantas daninhas na cultura do feijoeiro-comum em sistema de semeadura direta. Planta Daninha, Viçosa, v. 20, n. 2, p. 213-220, 2002. 
NEGRISOLI, E. VELINI, E.D.; TOFOLI, G. R. CAVENAGHI, A. L.; MARTINS, D. MORELLI, J. L.; COSTA, A. G. F. Seletividade de herbicidas aplicados em pré-emergência na cultura da cana-de-açúcar tratada com nematicidas. Planta Daninha, Viçosa, v. 22, n. 4, p. 567-575, 2004.

PARREIRA, M. C.; BARROSO, A. A. M.; PEREIRA, F. C. M.; ALVES, P. L. C. A. Modeling of weeds interference periods in bean. Planta daninha, Viçosa, v. 30, n. 4, p. 713-720, 2012

PITELLI, R. A. Interferência de plantas daninhas em culturas agrícolas. Informe Agropecuário, v. 11, n. 129, p. 16-27, 1985.

SALGADO, T. P.; SALLES, M. S.; MARTINS, J. V. F.; ALVES, P. L. C. A. Interferência das plantas daninhas no feijoeiro carioca. Planta Daninha, Viçosa, v. 25, n. 3, p. 443-448, 2007.

SANTOS, J.B.; CURY, J.P. Picão-preto: uma planta daninha especial em solos tropicais. Planta Daninha, Viçosa, v. 29, p. 1159-1171, 2011.

SILVA, A. A.; FERREIRA, F. A.; FERREIRA, L. R.; SANTOS, J. B. Competição entre plantas daninhas e culturas. In: SILVA, A. A.; SILVA, J. F. (Eds.). Tópicos em manejo de plantas daninhas. Viçosa: UFV, 2007. p. 17-61.

TEIXEIRA, I. R.; SILVA, R. P.; SILVA, A. G.; FREITAS, R. S. Competição entre feijoeiros e plantas daninhas em função do tipo de crescimento dos cultivares. Planta Daninha, Viçosa, v. 27, n. 2, p. 235-240, 2009.

TORRES, L. G.; FERREIRA, E. A.; ROCHA, P. R. R.; FARIA, A. T.; GONÇALVES, V. A.; GALON, L.; SILVA, A. F.; SILVA, A. A. Alterações nas características fisiológicas de cultivares de cana-de-açúcar submetida à aplicação de herbicidas. Planta daninha, Viçosa, v. 30, n. 3, p. 581-587, 2012. 